\title{
ANALYSIS OF NEUTRON FLUX DISTRIBUTION IN RSG-GAS REACTOR WITH U-Mo FUELS
}

\author{
Taswanda TARYO and T.M. SEMBIRING \\ Center for Development of Research Reactor Technology-BATAN, \\ Kawasan Puspiptek, Gedung 31, Serpong 15310, Tangerang, Indonesia \\ Phone : +62-21-7560908 Ext. 279; Fax : +62-21-756-0573; E-mail : t_taryo2273@yahoo.com
}

\begin{abstract}
ANALYSIS OF NEUTRON FLUX DISTRIBUTION IN RSG-GAS REACTOR WITH U-Mo FUELS. The use of U-Mo fuels in research reactors seems to be promising and, recently, world researchers have carried out these such activities actively. The National Nuclear Energy Agency (BATAN) which owns RSG-GAS reactor available in Serpong Research Center for Atomic Energy should anticipate this trend. It is, therefore, this research work on the use of U-Mo fuels in RSG-GAS reactor should be carried out. The work was focused on the analysis of neutron flux distribution in the RSG-GAS reactor using different content of molybdenum in U-Mo fuels. To begin with, RSG-GAS reactor core model was developed and simulated into $\mathrm{X}, \mathrm{Y}$ and $\mathrm{Z}$ dimensions. Cross section of materials based on the developed cells of standard and control fuels was then generated using WIMS-D5-B. The criticality calculations were finally carried out applying BATAN-2DIFF code. The results showed that the neutron flux distribution obtained in U-Mo-fuel-based RSG-GAS core is very similar to those achieved in the 300-gram sillicide-fuel-based RSG-GAS reactor core. Indeed, the utilization of the U-Mo RSG-GAS core can be very similar to that of the high-density sillicide reactor core and even could be better in the future.
\end{abstract}

Keywords : RSG-GAS core, U-Mo fuels, flux distribution.

\section{INTRODUCTION}

The multipurpose reactor G.A. Siwabessy (RSG-GAS) is a light water, open pool reactor and at present, RSG-GAS reactor core has full core of $\mathrm{U}_{3} \mathrm{Si}_{2}-\mathrm{Al}_{\mathrm{x}}$ fuels [1]. The sillicide core achieved $30 \mathrm{MW}$ thermal in September 2002. It is noted that $\mathrm{U}_{3} \mathrm{Si}_{2}-\mathrm{Al}_{x}$ fuels have the same size as $\mathrm{U}_{3} \mathrm{O}_{8}-\mathrm{Al}_{x}$ fuel's. It is, therefore concluded from many assessments already carried out that they have very similar neutronic and thermohydraulic characteristics, with $\mathrm{U}_{3} \mathrm{Si}_{2}-\mathrm{Al}_{x}$ fuels seem a bit better [2]. In the future, the sillicide fuels having density of $3.55 \mathrm{~g} / \mathrm{cc}$ and containing $300 \mathrm{~g}$ U-235 will be utilized for RSG-GAS compact core to make the reactor core more effective and efficient. However, come along with this objectives and to anticipate the trend to use U-Mo fuels in world research reactors, there are some assessments regarding the possibility to utilize U-Mo-Al fuels in RSG-GAS reactor. Sembiring et. al [3] already assessed the preliminary study on the utilization of U-Mo fuels in the RSG-GAS reactor and the results showed that the U6\% Mo-Al and U9\% Mo-Al fuels can be the candidate of equilibrium molybdenum cores for RSG-GAS reactor in the future. While for operation cycle length, both are the same, 32.5 days, the shutdown margin is 0.84 for U9\%Mo-Al fuels and 1.03 
for sillicide fuels. In addition, one of the other possible asessments for the above fuels in the RSG-GAS reactor is of the neutron flux distribution in the reactor core and this research work has, therefore, to be carried out. By recognizing the neutron flux distribution in the reactor core in detail, the reactor utilization can be effectively, efficiently managed.

To begin with, a model has been developed as a basis of simulation where the RSG-GAS core was represented as mesh points along $\mathrm{X}, \mathrm{Y}$ and $\mathrm{Z}$ directions. Based on that model, cell calculation of the fuel and absorber was then developed. To simulate all previous calculations, the verified WIMSD5-B and BATAN-2DIFF codes were utilized as the main tools [4,5]. While WIMS-D5-B operated in MTR-PC System INVAP has been applied to generate group diffusion parameters, BATAN-2DIFF was activated to estimate effective multiplication factor $\left(k_{\text {eff }}\right)$, neutron flux distribution, reactivity worth of the reactor core, power peaking factor and others in more detail.

\section{THEORETICAL BACKGROUND}

\section{Description of Computer Codes Applied.}

As previously mentioned, code WIMS-D5-B was applied to generate group diffusion parameters. WIMS-D5-B code is a general lattice cell program which uses transport theory to estimate flux as a function of energy and position in the cell. In the interests of economy of machine time this is done in two steps : WIMS-D5-B first calculates spectra for few spatial regions in the full number of energy groups of its library, and uses these spectra to condense the basic cross-section into few groups. A few group calculation are then carried out using a much more detailed spatial representation. The resulting fluxes are then expanded using the spectra of the previous calculation, so that the reaction rates at each spatial point can be calculated in the library group structure.

Whilst the group structure required by the program from the library tape is arbitrary, basic libraries of WIMS-D5-B are available in 58 and 69 groups, the latter having an increased number of fast and resonance groups and being now generally recommended. Homogenized 69 groups cross section based on standard WIMS-D5-B library are generated by treating in one dimensional domain fuel, cladding coolant and extra region as a single zone. Based on lattice description eight and nine mixtures or burn-up levels were generated for IAEA benchmark.

Once the macroscopic cross sections have been calculated and transformed into collision probabilities, the 69 energy group equations can be formulated and the neutron flux in each group can be calculated. However, criticality equations with such a number of energy groups will require a very high computation time and due to the accuracy of available nuclear data will 
not achieve too much better computation accuracy compared to few-group model. Therefore, to substantially reduce the computation time, the structure of the four energy groups is normally used, i.e., 10 to $0.821 \mathrm{MeV}, 0.821 \mathrm{MeV}$ to $1.855 \mathrm{eV}, 1.855 \mathrm{eV}$ to $0.625 \mathrm{eV}$ and $0.625 \mathrm{eV}$ to $0 \mathrm{eV}$.

Using a simplified representation of the geometry together with the full number of 69 library groups, WIMS-D5-B computes for each cell, four distinct condensation spectra appropriate to fuel, cladding, coolant and extra region. The result of the first part of WIMS-D5-B calculations consist of multi-group fluxes for 4 regions of a cell, $k$ infinity for the representative cell and few group macroscopic cross section of all materials.

As previously stated, BATAN-2DIFF was activated to estimate effective multiplication factor $\left(k_{\text {eff }}\right)$, neutron flux distribution, reactivity worth of the reactor core, power peaking factor and others in more detail. The code was utilized on a production basis for solving problems involving a finitedifference diffusion theory representation of neutron transport theory. The code is designed to solve depletion problems with or without elaborate refueling treatment for multi-cycle analysis. Depletion problems can be solved and fuel managed for multi-cycle analysis. Extensive first order perturbation results may be obtained given macroscopic data and nuclide concentrations. The code results in estimating effective multiplication factor $\left(k_{\text {eff }}\right)$, reactivity worth of the reactor core, power peaking factors and others in more detail.

\section{METHOD OF ANALYSIS}

\section{Cell Calculation}

Basically, one applied reactor physics design scheme in Figure 1. There was no concern about the A process, since this part (ENDF/VI) is already provided [6]. Actually, the general step of the calculation flow is to start with small system such as pin cell (B1) and to proceed via intermediate systems, such as, fuel assembly (B2) to the whole core calculation (C). The calculation procedures start from a detailed to a crude representation of the energy and space variables. The flux obtained in each phase is used to produce cross section for the next phase, after condensation and homogenization. In order to compute the cell averaged thermal group constants for a few region cell, it is important to perform, first, a thermal spectrum calculation for an infinite medium with the number densities of fuel and moderator being uniformly distributed over the cell, and second to determine the disadvantage factors characterizing the cell. Models of cells for standard and control fuels of RSG-GAS reactor can be respectively seen in Figures 2 and 3. 


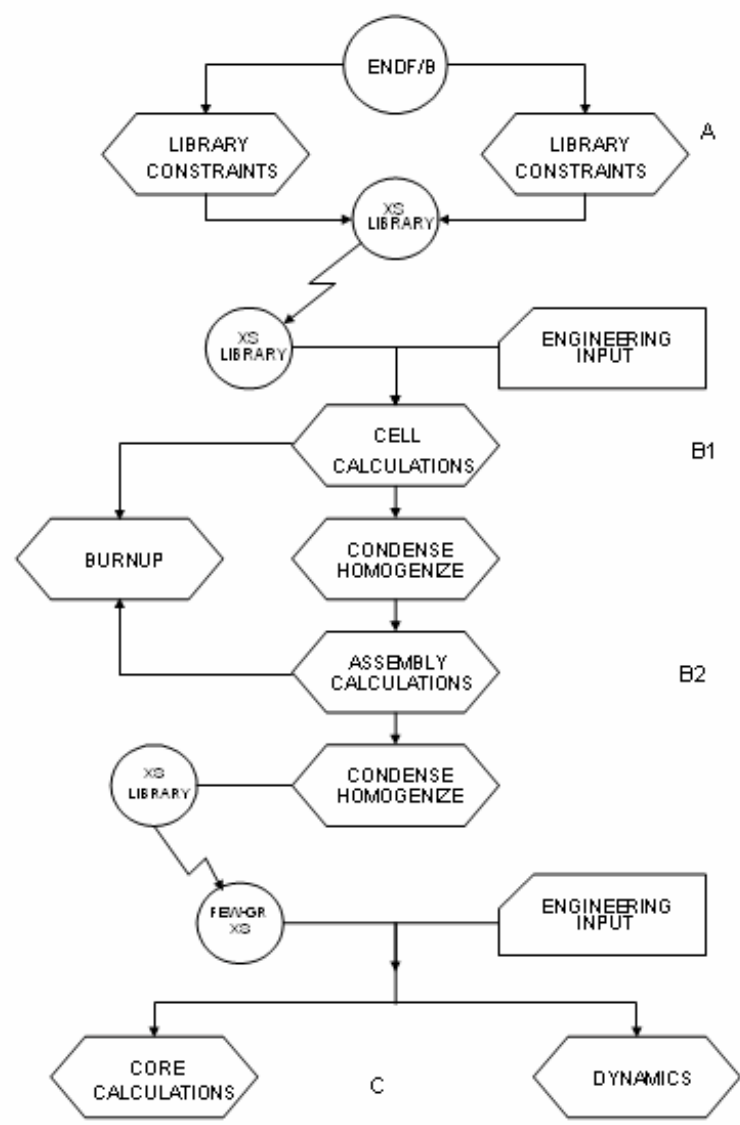

Figure 1. Reactor physics calculation scheme [9].

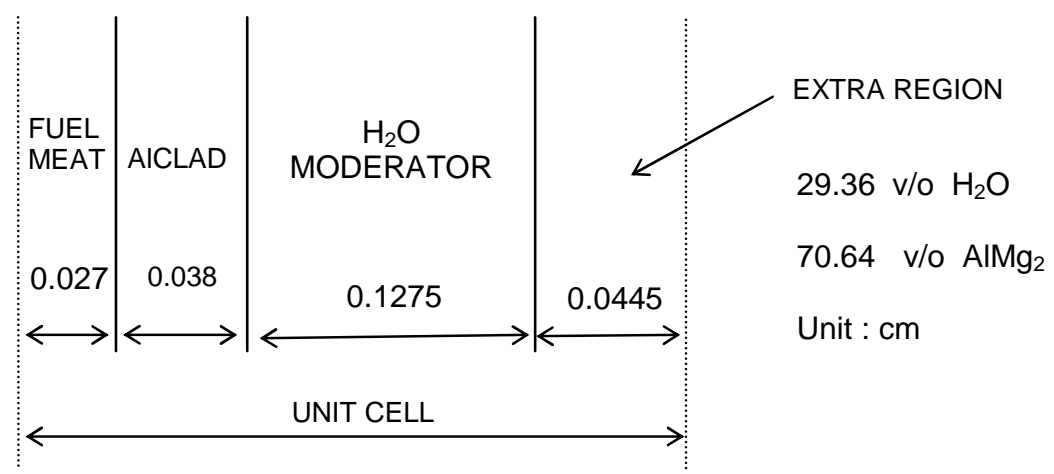

Figure 2. Cell model for standard element of RSG-GAS reactor. 


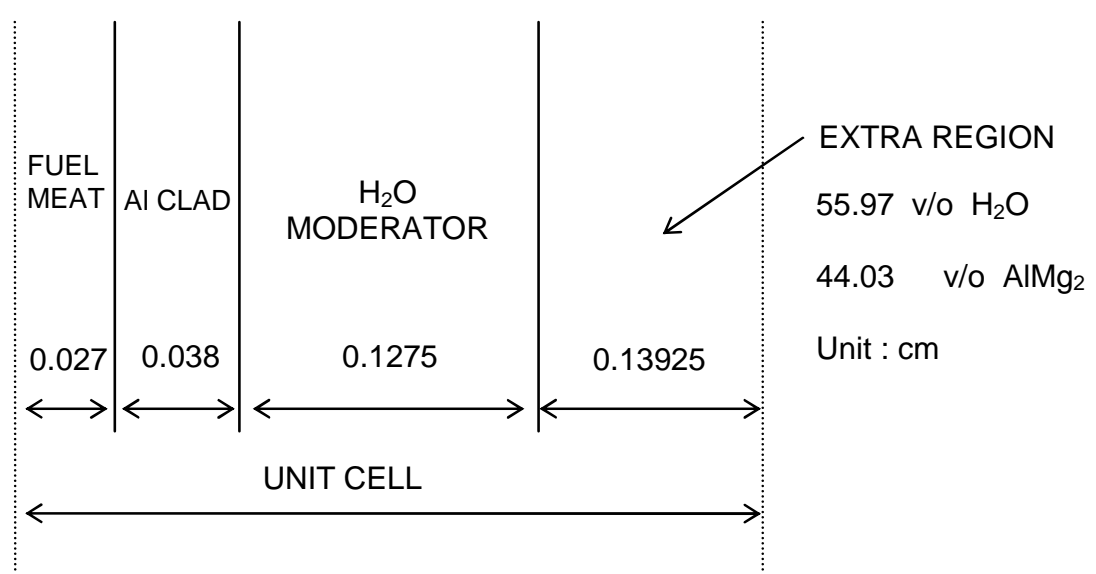

Figure 3. Cell model for control element of RSG-GAS reactor.

\section{Lattice Modeling}

Neutronic modeling consists of two separate parts. First, lattice cell calculations to determine group constants. This was needed for the second part for whole core calculations. To validate the calculation model and method, a benchmark problem defined by IAEA, was used as a reference [7]. The one dimensional WIMS-D5-B code was used for lattice cell calculation for all materials in the core such as fuels with certain burn-up levels, Beryllium reflectors and voids within the reactor core.

With the basic 69 group library available in WIMS-D5-B, the cell calculations was done using the one dimensional models in the code. Construction of the 4 group data was performed by six important steps. The 4 energy group boundaries are $10 \mathrm{MeV}, 0.821 \mathrm{MeV}, 5.531 \mathrm{keV}, 0.625 \mathrm{eV}$ and $0 \mathrm{eV}$. Starting with the geometry and materials specification, the macroscopic cross section computations was computed from library cross sections and number densities up to changes of fuel composition due to fuel burn-up in MWD/THM. The unit cell used in the infinite slab geometry consisted of fuel, clad, water having their actual thickness, and an extra region with the appropriate thickness and composition to include the remaining water and aluminum in the same proportions as in the physical fuel element. The cell calculations was accomplished by WIMS-D5-B. The cell calculations will be performed by the slab geometry option of the collision probability routine in WIMS-D5-B to obtain the cell averaged 4 group constants which will be employed for whole core calculation. The cross section data sets as a function of expected burn-up steps will be generated by WIMS-D5-B code, a general lattice cell program based on transport equation to calculate flux as a function of energy and position in the cell. Three steps calculation by WIMS-D5-B consists of spectrum calculation for a few spatial region in full 69 energy 
groups of its library, then the spectrum is used to condense the basic cross sections into few groups in a detailed spatial representation, followed by the third step for leakage correction and time dependent burn-up calculation.

For the whole core calculation the two and three dimensional multigroup diffusion code, BATAN-2DIFF code will be applied. The calculations will be performed in $x-y-z$ geometry consisting of $4 x 4$ meshes per assembly for typical working core. Using this procedure, the power and flux distribution, temperature coefficients and control rod worth will be determined for the RSG-GAS typical working core.

\section{Criticality Calculcation}

A remarkable diffusion code, called BATAN-2DIFF, were used here to determine the multiplication factor of the reactor core, the power distribution and, especially, the flux distribution in the vicinity of the control rods. The BATAN-2DIFF code developed by BATAN can treat two and three dimensional problems in the reactor core and the IAEA benchmark problem had been adopted to validate the BATAN code. While the maximum difference for the average thermal flux is $4.4 \%$, the thermal fluxes at the center and at the center midplane of the same reactor only deviated $2.9 \%$ [8].

In the present calculation, the RSG-GAS core is simulated with regions in each of which the material properties are uniform. All cross sections derived from WIMS-D5-B are constant within a region; only fluxes and the total neutron source are spatially dependent within a region. Neutron diffusion equations are solved numerically across the entire reactor core (core, reflector and the region beyond linear extrapolation distance) by using proper boundary and interface conditions. Diffusion equation is replaced by an approximately equivalent system of finite difference equations, accomplished by imposing on each of the regions a number of equally sized mesh intervals and then approximating the derivatives terms by their finite difference analog on the mesh points. The mesh intervals are constant within a region, but may vary from region to region. The mesh intervals are chosen to be sufficiently small that the flux is practically linear between adjacent mesh points.

By applying the first and second derivatives of the flux at each point, each of the group differential equations has been replaced by $\mathrm{N}$ algebraic equations and by making use of the three point recursion relation for the flux in the group for one dimensional calculation, an equation is obtained which is valid at all points except on interfaces. All equations will have three unknown fluxes, two of which are common in every two adjacent equations. The single value can be determined from the boundary condition at the mean and outer boundary of the assembly. In the case of 2 dimensional calculation such as using BATAN-2DIFF, the five point difference equations are involved.

An initial guessed source distribution S (source), which is decided by a user, is normalized and assigned at each mesh point to begin the first iteration. 
With this source distribution, the finite difference equation is solved for group 1 until group 4. After the flux has been computed in all groups, a new fission source distribution is computed from the flux distribution. This source distribution is used for the next iteration called outer iteration. This procedure is repeated until either the specified convergence criterion is met, i.e for $\mathrm{k}_{\text {eff }}, \mathrm{e}_{1} \approx 10^{-5}$ and for flux, $\mathrm{e}_{2} \approx 10^{-4}$.

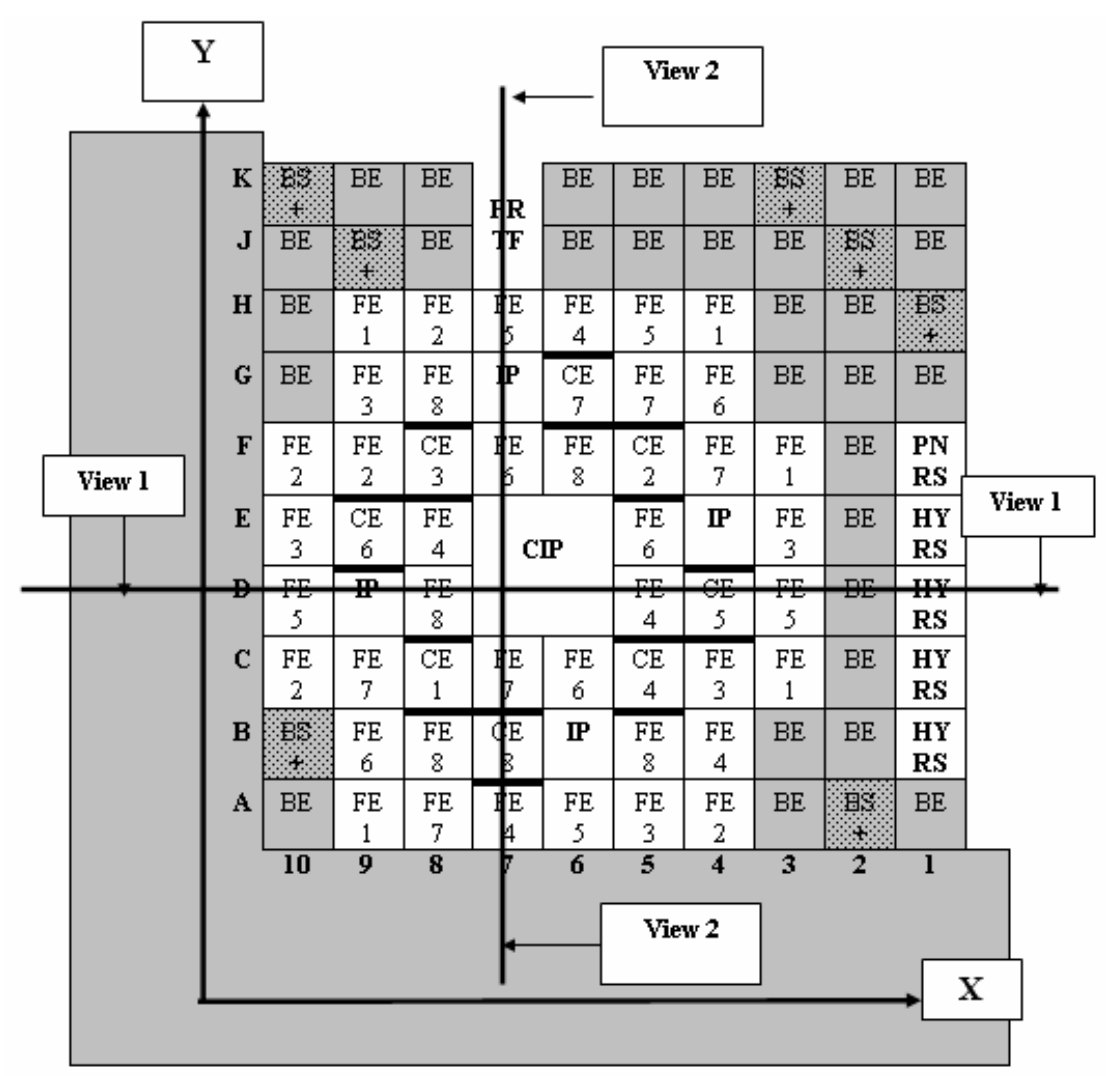

BERYLLIUM BLOCK REFLECTOR

Figure 4. Lay out of RSG-GAS neutron fluxes taken into account.

\section{RESULTS AND DISCUSSION}

\section{General}

The results of neutron flux distribution are obtained in 4 energy neutron groups, namely, fast neutron, $10 \mathrm{MeV}<\mathrm{E}<0.821 \mathrm{MeV}$ (group 1); resonance neutron, $0.821 \mathrm{MeV}<\mathrm{E}<5.531 \mathrm{keV}$ (group 2); epithermal neutron, $5.531 \mathrm{keV}<\mathrm{E}<0.625 \mathrm{eV}$ (group 3) and thermal neutron, $0.625 \mathrm{eV}$ $<\mathrm{E}<0$ (group 4). Basically, each grid consists of many mesh points and the 
neutron flux results estimated are average neutrons in every grid of the RSG-GAS core. One simply estimates the average neuton in each grid by summation of multiplying each flux in each grid to the area of each mesh. The average neutron flux is then achieved by dividing the above summation to the total area of mesh points in the grid.

For this analysis, as explained earlier, there are three analysis considering three kinds of fuels, namely, fuel U6Mo300-Al meaning the content of Molybdenum 6\% and 300 gr U-235; fuel U9Mo300-Al taking into account the density of $9 \%$ for Molybdenum with the same content of U-235 and finally fuel USi300-Al meaning that each sillcide fuel contains $300 \mathrm{gr}$ U-235. To make it logic, the use of U-Mo fuels will be compared to that of U-Si fuels using the same content of $300 \mathrm{gr}$ U-235. In addition, there are a lot of analysis concerning the comparation between the use of U-Si fuels containing 300 gr U-235 and that containing 250 gr U-235. From the safety point of view, the former is not significantly diiferent with the latter $[2,11]$. The following sub section will then perform fast and thermal neutron fluxes occuring in the RSG-GAS core using different fuels and finally the ratios of each molybdenum fuel to sillicide fuels using the same $300 \mathrm{gr}$ U-235 per standard fuel and $214.29 \mathrm{gr} \mathrm{U}-235$ per control fuel.

\section{Neutron Flux Distribution using Different Fuels in RSG-GAS Core (View 1)}

As seen in Figure 4, the RSG-GAS reactor core has 4 irradiation positions (IP's), central irradiation position (CIP), power ramp test facility (PRTF), 5 rabbit systems (fast and normal) which can be used for radioisotopes and exprimental activities. The neutrons both for fast and thermal are seen from view 1 and view 2. The view 1 goes through grid D10 to grid D1 and this view expresses neutrons in fuel elements (FE), irradiation position (IP), central irradiation position (CIP) and normal rabbit system (NRS).

For fast neutrons, for all fuels as seen in view 1, most of all fast neuton fluxes occur in RSG-GAS and for every grid taken into account are in the order of $10^{13} \mathrm{n} / \mathrm{cm}^{2} \mathrm{sec}$. This is due to newly neutrons generated and slowing down to lower neutron energy groups promptly. In addition, the detail fast neutron of each grid previously mentioned can be seen in Table 1. As seen in the Table, the fast neutrons (group 1) taking place in rabbit system are the lowest ones because the position of the rabbit system is at the edge of the reactor core. Finally, one can see from the same Table, the ratio of fast neutron fluxes occuring in U6Mo and U9Mo fuels to USi fuel is in the range of $0.9912(-0.18 \%)$ to $1.0085(+0.85 \%)$ and thereby meaning the maximum deviation only around $0.85 \%$.

For thermal neutrons, for all fuels as seen through view 1, most of all thermal neuton fluxes occuring in RSG-GAS core for every grid taken into 
account are in the order of $10^{14} \mathrm{n} / \mathrm{cm}^{2} \mathrm{sec}$. While the detail thermal neutron of each grid previously mentioned is explored in Table 2, a 3D representation of thermal neutron fluxes distribution occuring in RSG-GAS core using U6Mo300-Al are shown in Figure 5. In this case, the highest thermal neutron flux takes place in CIP because it contains only water moderator generating high density of neutrons and the flux is in the order of $2.40 \times 10^{14} \mathrm{n} / \mathrm{cm}^{2} \mathrm{sec}$. Again, the thermal neutrons happening in rabbit systems are the lowest ones because the position of the rabbit system is at the edge of the reactor core. From Table 2, it is noted that the fast neutron fluxes are lower than thermal neutron's in the same FE, because, only fast neutron flux (group 1) was estimated. Finally, the ratio of thermal neutron fluxes occuring both in U6Mo and in U9Mo fuels to USi fuel is in the range of $0.9742(-2.60 \%)$ to $1.0056(+0.56 \%)$ and thereby meaning the maximum deviation is only $2.60 \%$.

Table 1 . The view 1 fast neutron flux of RSG-GAS core using different fuels

\begin{tabular}{|c|c|c|c|c|c|c|c|c|}
\hline Fuels & $\begin{array}{c}\text { D8 } \\
\text { (FE) }\end{array}$ & $\begin{array}{l}\text { D7 } \\
\text { (IP) }\end{array}$ & $\begin{array}{c}\text { D6 } \\
\text { (FE) }\end{array}$ & $\begin{array}{c}\text { D5 } \\
\text { (CIP) }\end{array}$ & $\begin{array}{c}\text { D4 } \\
\text { (CIP) }\end{array}$ & $\begin{array}{c}\text { D3 } \\
\text { (FE) }\end{array}$ & $\begin{array}{c}\mathrm{D} 2 \\
\text { (FE) }\end{array}$ & $\begin{array}{c}\text { D1 } \\
\text { (NRS) }\end{array}$ \\
\hline U6Mo300 & 0.7388 & 0.6910 & 0.7831 & 0.5381 & 0.5555 & 0.8753 & 0.7637 & 0.0791 \\
\hline U9Mo300 & 0.7386 & 0.6921 & 0.7858 & 0.5399 & 0.5568 & 0.8759 & 0.7625 & 0.0789 \\
\hline USi300 & 0.7409 & 0.6924 & 0.7795 & 0.5353 & 0.5530 & 0.8730 & 0.7653 & 0.0796 \\
\hline Ratio U6M/Si & 0.9971 & 0.9979 & 1.0046 & 1.0052 & 1.0045 & 1.0026 & 0.9979 & 0.9937 \\
\hline RatioU9M/Si & 0.9968 & 0.9995 & 1.0080 & 1.0085 & 1.0068 & 1.0033 & 0.9963 & 0.9912 \\
\hline
\end{tabular}

Note : FE - Fuel element; IP - Irradiation position; CIP - Central irradiation position $\mathrm{Be}$ - Berryllium reflector element; NRS - Normal rabbit system.

Table 2. The view 1 thermal neutron flux of RSG-GAS core using different fuels $\left(\times 10^{14} \mathrm{n} / \mathrm{cm}^{2} \mathrm{sec}\right)$.

\begin{tabular}{|l|c|c|c|c|c|c|c|c|}
\hline \multicolumn{1}{|c|}{ Fuels } & $\begin{array}{c}\text { D8 } \\
(\mathrm{FE})\end{array}$ & $\begin{array}{c}\text { D7 } \\
(\mathrm{IP})\end{array}$ & $\begin{array}{c}\text { D6 } \\
(\mathrm{FE})\end{array}$ & $\begin{array}{c}\text { D5 } \\
\text { (CIP }\end{array}$ & $\begin{array}{c}\text { D4 } \\
(\mathrm{CIP})\end{array}$ & $\begin{array}{c}\text { D3 } \\
(\text { FE) }\end{array}$ & $\begin{array}{c}\text { D2 } \\
(\text { FE) }\end{array}$ & $\begin{array}{c}\text { D1 } \\
(\text { NRS) }\end{array}$ \\
\hline U6Mo300 & 0.9491 & 2.0887 & 1.2141 & 2.4188 & 2.4160 & 1.0160 & 0.8599 & 0.8199 \\
\hline U9Mo300 & 0.9438 & 2.0844 & 1.2064 & 2.4199 & 2.4173 & 1.0116 & 0.8535 & 0.8177 \\
\hline USi300 & 0.9678 & 2.1288 & 1.2339 & 2.4223 & 2.4196 & 1.0335 & 0.8796 & 0.8279 \\
\hline Ratio U6M/Si & 1.0056 & 0.9811 & 0.9839 & 0.9985 & 0.9985 & 0.9830 & 0.9776 & 0.9903 \\
\hline RatioU9M/Si & 0.9752 & 0.9791 & 0.9777 & 0.9990 & 0.9990 & 0.9788 & 0.9703 & 0.9876 \\
\hline
\end{tabular}

Note : FE - Fuel element; IP - Irradiation position; CIP - Central irradiation position $\mathrm{Be}$ - Berryllium reflector element; NRS - Normal rabbit system. 


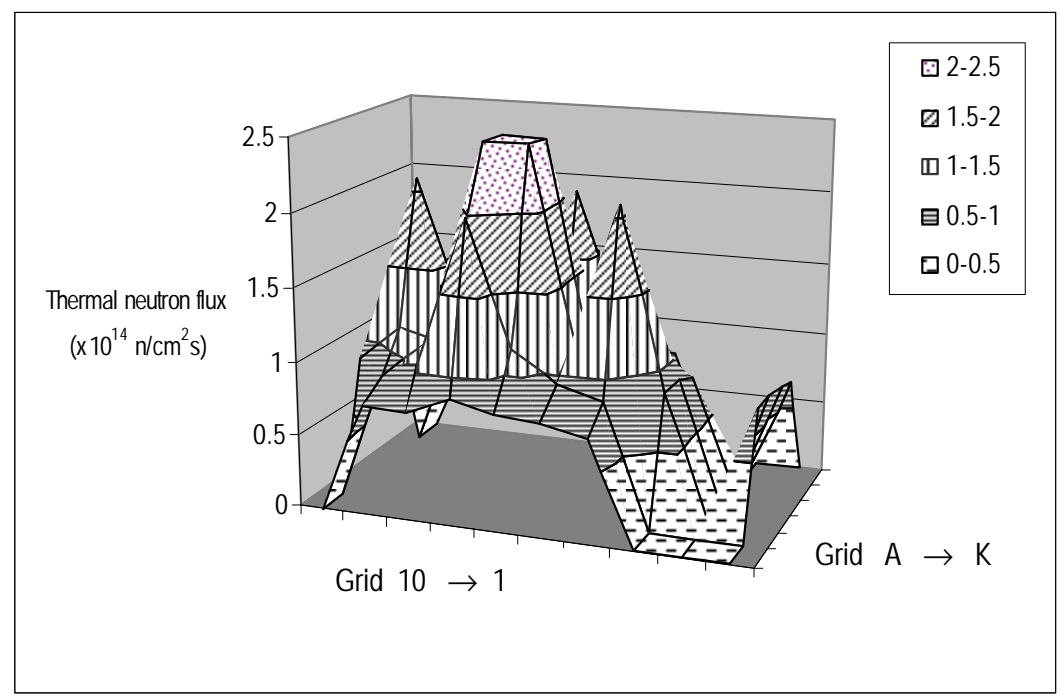

Figure 5. Thermal neutron fluxes in RSG-GAS core using U6Mo300-Al fuels.

\section{Neutron Flux Distribution using Different Fuels in RSG-GAS Core (View 2)}

Investigation of view 2 on neutron flux distribution moves from grid K7 to grid A7 and this view passes PRTF, IP, CIP, FE and CE. For fast neutrons, for all fuels as seen in view 2, most of all fast neuton fluxes happening in RSG-GAS for every grid taken into account are in the order of $10^{13} \mathrm{n} / \mathrm{cm}^{2} \mathrm{sec}$. In addition, thermal neutron fluxes are higher due to more neutrons generated and slowed down to lower neutron energy groups. The detail fast neutron of each grid previously mentioned is displayed in Table 3. For every fuel, the fast neutron fluxes taking place in CIP are lower than those in FE, because, fuel elements (FE) as fission materials more produce neutrons in the reactor core. Other than that, the fast neutrons happening in PRTF are the lowest ones because the PRTF position is exactly at the edge of the reactor core, the same as the rabbit system position. It is finally noted that the ratio of fast neutron fluxes occuring in U6Mo and U9Mo fuels to USi fuel is in the range of $0.9879(-1.21 \%)$ to 1.0183 $(+1.83 \%)$. The maximum difference of Mo fuels to Sillicide fuels containing 300 gr U-235 is indeed only around $1.83 \%$.

For thermal neutrons, for all fuels as seen in view 2, most of all thermal neuton fluxes arising in RSG-GAS for every grid taken into account are in the order of $10^{14} \mathrm{n} / \mathrm{cm}^{2} \mathrm{sec}$. The detail thermal neutrons of each grid previously mentioned are performed in Table 4. A 3D representation of thermal neutrons fluxes occuring in the RSG-GAS core using U9Mo300-Al 
and USi300-Al fuels are respectively shown in Figures 6 and 7. Furthermore, the highest thermal neutron fluxes occur in CIP because it contains only water moderator/coolant generating high density of neutrons and the CIP flux is in the order of $2.40 \times 10^{14} \mathrm{n} / \mathrm{cm}^{2}$ sec. Other than that, the thermal neutrons occuring in a rabbit system are the lowest one because the position of the rabbit system is indeed at the edge of the reactor core which accept much less neutrons compared to others. From Tables 3 and 4, it is noted that the fast neutron fluxes are lower than thermal neutron's in the same FE, because, only fast neutron flux (group 1) was estimated.Indeed. Finally, the ratio of thermal neutron fluxes taking place in U6Mo and U9Mo fuels to USi fuel is in the range of $0.9772(-2.28 \%)$ to $0.9990(-0.10 \%)$ and hence meaning the maximum deviation only around $2.28 \%$.

From current investigation on the flux ratio of two kinds of Mo fuels to Sillicide fuels previously mentioned, the difference is very small, only maximum $2.6 \%$. From reactor utilization point of view, this small difference will not influence the activity of the RSG-GAS reactor utilization at all and hence meaning nothing for all research activites carried out in the reactor core. This could be much better from utilization point of view if a compact RSG-GAS core which is really a more effective and efficient reactor core developed.

Table 3. The view 2 fast neutron flux of RSG-GAS core using different fuels

\begin{tabular}{|c|c|c|c|c|c|c|c|c|}
\hline Fuels & $\begin{array}{c}\text { K7 } \\
\text { (PRTF) }\end{array}$ & $\begin{array}{c}\text { J7 } \\
\text { (PRTF) }\end{array}$ & $\begin{array}{c}\mathrm{H} 7 \\
(\mathrm{FE})\end{array}$ & $\begin{array}{c}\text { F7 } \\
(\mathrm{FE})\end{array}$ & $\begin{array}{c}\text { E7 } \\
\text { (CIP) }\end{array}$ & $\begin{array}{c}\text { D7 } \\
\text { (CIP) }\end{array}$ & $\begin{array}{c}\mathrm{C7} \\
(\mathrm{FE})\end{array}$ & $\begin{array}{c}\text { A7 } \\
(\mathrm{FE})\end{array}$ \\
\hline U6Mo300 & 0.1314 & 0.1314 & 0.7563 & 0.9727 & 0.8848 & 0.7831 & 0.8728 & 0.6461 \\
\hline U9Mo300 & 0.1312 & 0.1312 & 0.7543 & 0.9720 & 0.8853 & 0.7858 & 0.8751 & 0.6487 \\
\hline USi300 & 0.1321 & 0.1321 & 0.7635 & 0.9827 & 0.8874 & 0.7795 & 0.8681 & 0.6370 \\
\hline Ratio U6M/Si & 0.9947 & 0.9947 & 0.9905 & 0.9898 & 0.9970 & 1.0046 & 1.0054 & 1.0142 \\
\hline RAtioU9M/Si & 0.9931 & 0.9931 & 0.9879 & 0.9891 & 0.9976 & 1.0080 & 1.0080 & 1.0183 \\
\hline
\end{tabular}

Note : PRTF - power ramp test facility; CIP - central irradiation position; FE fuel element.

Table 4. The view 2 thermal neutron flux of RSG-GAS core using different fuels $\left(x_{10}^{14} \mathrm{n} / \mathrm{cm}^{2} \mathrm{sec}\right)$.

\begin{tabular}{|c|c|c|c|c|c|c|c|c|}
\hline Fuels & $\begin{array}{c}\text { K7 } \\
\text { (PRTF) }\end{array}$ & $\begin{array}{c}\text { J7 } \\
\text { (PRTF) }\end{array}$ & $\begin{array}{c}\text { H7 } \\
\text { (FE) }\end{array}$ & $\begin{array}{c}\text { F7 } \\
\text { (FE) }\end{array}$ & $\begin{array}{c}\text { E7 } \\
(\text { CIP })\end{array}$ & $\begin{array}{c}\text { D7 } \\
(\text { CIP })\end{array}$ & $\begin{array}{c}\text { C7 } \\
(\text { FE })\end{array}$ & $\begin{array}{c}\text { A7 } \\
(\text { FE })\end{array}$ \\
\hline U6Mo300 & 1.2261 & 1.2261 & 0.8632 & 1.1318 & 2.4314 & 2.4188 & 1.0601 & 0.8137 \\
\hline U9Mo300 & 1.2237 & 1.2237 & 0.8580 & 1.1250 & 2.4319 & 2.4199 & 1.0550 & 0.8112 \\
\hline USi300 & 1.2296 & 1.2296 & 0.8760 & 1.1514 & 2.4423 & 2.4223 & 1.0730 & 0.8172 \\
\hline Ratio U6M/Si & 0.9971 & 0.9971 & 0.9853 & 0.9829 & 0.9955 & 0.9985 & 0.9879 & 0.9957 \\
\hline RatioU9M/Si & 0.9952 & 0.9952 & 0.9794 & 0.9770 & 0.9957 & 0.9990 & 0.9832 & 0.9926 \\
\hline
\end{tabular}

Note : PRTF - power ramp test facility; CIP - central irradiation position; FE fuel element 


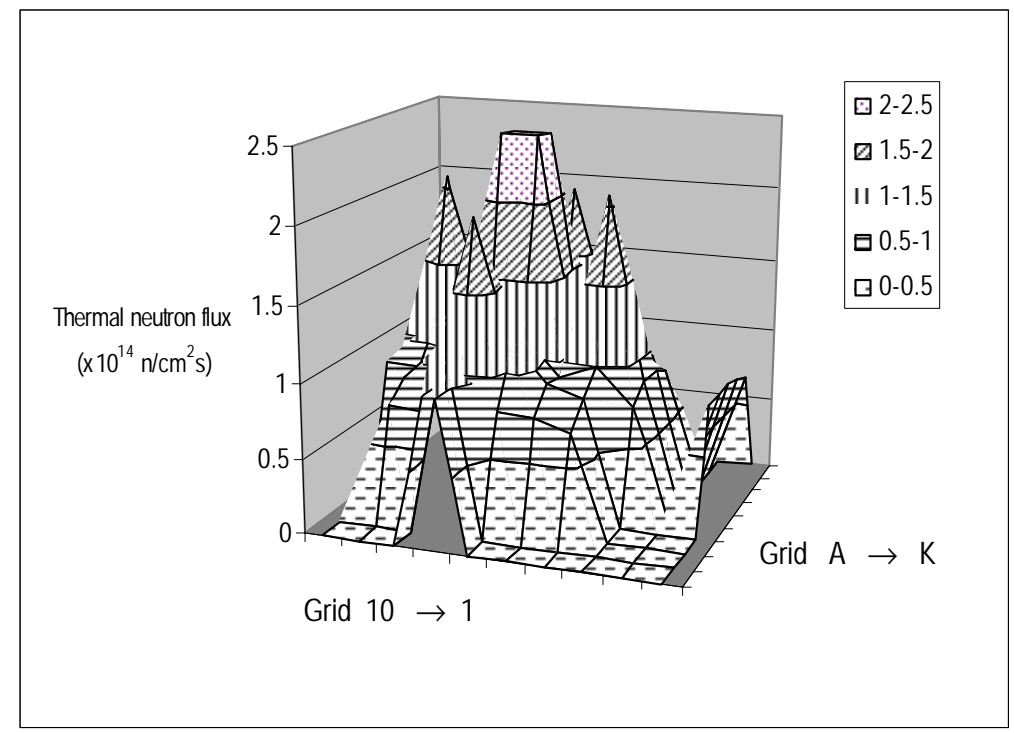

Figure 6. Thermal neutron fluxes in RSG-GAS core using U9Mo300-Al fuels.

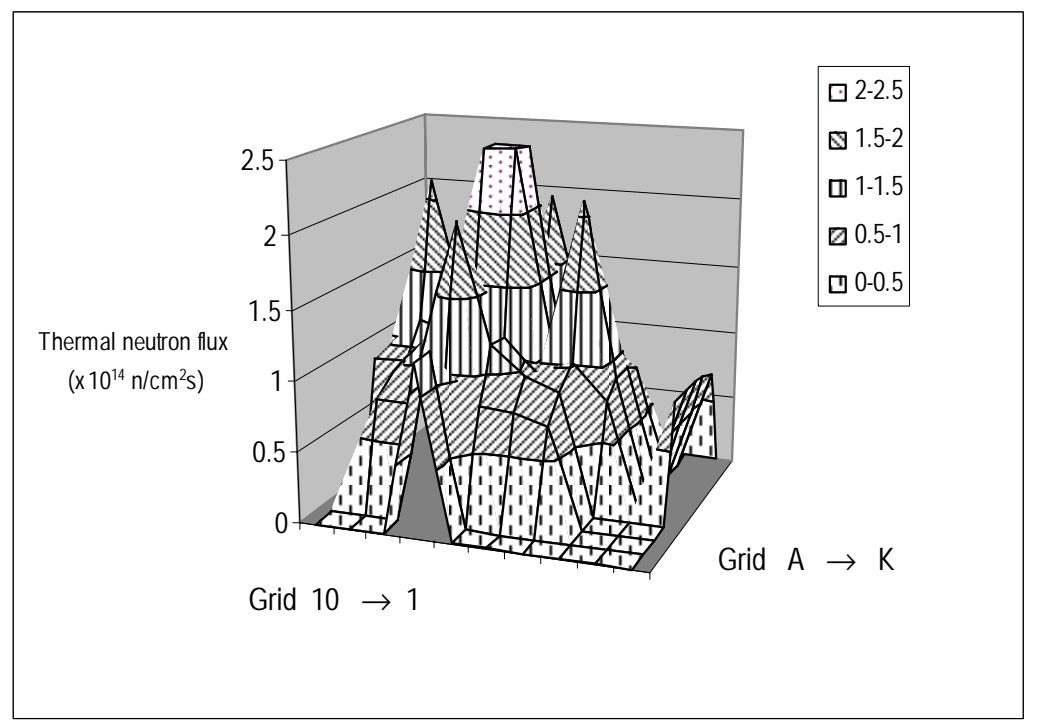

Figure 7. Thermal neutron fluxes in RSG-GAS core using USi300-Al fuels. 


\section{CONCLUSION}

From all results discussed in the previous section, it can be concluded that the RSG-GAS reactor core using U-Mo fuels with the density containing $300 \mathrm{gr} \mathrm{U}-235$ will be of the promising utilization of the reactor core due to high neutron fluxes distribution achieved. Indeed, the utilization of the U-Mo RSG-GAS reactor will be very similar to that of the Sillicide fuel containing 300 gr U-235 and even could be better in the future if a compact RSG-GAS reactor core developed.

\section{ACKNOWLEDGMENT}

The authors would like to express their gratefulness to Mr. Surian Pinem, Head of Neutronic Group as well as Dr. Setiyanto, Head of Division for Development of Reactor Technology-P2TRR, for their valuable corrections on the manuscript.

\section{REFERENCES}

1. BATAN, Safety Analysis Report, Multipurpose Reactor G.A. Siwabessy, Rev.8, Jakarta (1992)

2. LIEM, P.H., ARBIE, B., PRAYOTO and NABBI, R., "Fuel Management Strategy for the New Equilibrium Silicide Core Design of RSG GAS (MPR-30)", Nuclear Engineering Design, 120 (1998)

3. SEMBIRING, T.M., "Preliminary Study on the Utilization of U-Mo Fuel RSG-GAS Reactor", will be presented in the $8^{\text {th }}$ International Topical Meeting on Research Reactor vuel Management, Muenich Germany (2004)

4. FAYERS, F.J, DVISON, W and GEORGE, C.H., HALSALL, M.J, "LWR WIMS-D5-B : A Modular Computer Code for the Evaluation of Light Water Reactor Lattices, Part I, Description of Methods", AEEW.R 785, (1972)

5. FOWLER,T.B., VONDY, D.R. and CUNNINGHAM, G.W, "Nuclear Reactor Core Analysis Code : BATAN-2DIFF", ORNL-TM-2496, Revision 2, ORNL and Union Carbide Corporation (1971)

6. HONECK, H.C.,'ENDF/B-Specifications for an Evaluated Nuclear Data File for Reactor Applications", Brookhaven National Laboratory Report BNL-50066, (1966) 
7. IAEA, "Research Reactor Core Conversion from the Use of Highly Enriched Uranium to the Use of Low Enriched Uranium Fuels Guidebook", IAEA-TECDOC-233, Vienna, (1980)

8. SEMBIRING, T.M., LIEM, P.H.,"Validation of BATAN'S Standard Diffusion Codes on IAEA Benchmark Static Calculations", Atom Indonesia 23, 73-91 (1997)

9. ARBIE, B., "Oxide to Silicide Fuel Conversion Study for Multipurpose Reactor G.A. Siwabessy", Ph.D. Dissertation, University of Gadjah Mada, Yogyakarta, Indonesia, (1996) 